\title{
Considerações sobre Políticas de Saúde em Contextos de Redemocratização e Reformas Econômicas: os Casos Recen- tes de Argentina, Brasil e Chile
}

\author{
Wagner Iglecias (t) \\ Ursula Dias Peres ${ }^{(*)}$ \\ Cristiane Kerches da Silva Leite ${ }^{(+\cdots)}$
}

Resumo: Este artigo aborda os processos de implementação de políticas públicas de saúde nas duas últimas décadas a partir da comparação dos casos argentino, brasileiro e chileno. Embora influenciados pela agenda internacionalmente difundida pelo Banco Mundial, e imersos numa dinâmica concomitante de reformas econômicas e redemocratização política, os processos apresentam resultados diferentes em cada país. A partir da análise da literatura percebe-se que variáveis domésticas como as relações entre instituições políticas e intergovernamentais desempenham um papel muito relevante na construção das redes de proteção social nos três contextos analisados.

Palavras-chave: Políticas públicas de saúde, Reformas Econômicas, Redemocratização, Instituições Multilaterais, Instituições Políticas e Intergovernamentais.

\begin{abstract}
This article addresses the process of implementing public health policies in the last two decades by comparing the cases of Argentina, Brazil and Chile. Although influenced by the international World Bank agenda, and, concurrently immersed in a dynamic of economic reforms and of political redemocratization, these processes have had different results in each country. In the literature review it is clear that domestic variables, such as the relationship between political institutions and intergovernmental organizations, play a major role in building social safety nets in three contexts analyzed.
\end{abstract}

Keywords: Public health policies, Economic Reforms; Redemocratization, Multilateral Institutions, Political and Intergovernmental Institutions.

\footnotetext{
(*) Professor doutor da Escola de Artes, Ciências e Humanidades da Universidade de São Paulo e Programa de Pós-Graduação em Integração da América Latina da Universidade de São Paulo — Prolam/USP. E-mail:<wi6@usp.br.>

(**) Professor doutor da Escola de Artes, Ciências e Humanidades da Universidade de São Paulo. E-mail: <uperes@usp.br>.

(米*) Professor doutor da Escola de Artes, Ciências e Humanidades da Universidade de São Paulo. E-mail: $<$ ckerches@uol.com.br>. Recebido em 10.6.2010 e aceito em 9.5.2011
} 


\section{INTRODUÇÃO}

O presente texto discute os processos político-institucionais de implementação de políticas de saúde na América do Sul, a partir da perspectiva comparada entre os casos argentino, brasileiro e chileno. Os países latino-americanos passaram nas duas últimas décadas por processos de redemocratização conjugados com reformas econômicas liberalizantes. No mesmo período, defrontaram-se com o desafio de implementar uma agenda de políticas sociais difundida internacionalmente, na qual a descentralização administrativa e a busca pela eficiência adquiriram centralidade, como demonstram as reformas nos sistemas de proteção social desses países nos últimos anos. Contudo, não é possível entender o processo de implementação desses sistemas descentralizados somente a partir da influência de organismos internacionais, como o Banco Mundial. A literatura que analisa as reformas nesses países demonstra que há grandes diferenças, especialmente em virtude de fatores político-institucionais relacionados ao funcionamento de seus sistemas políticos (relações entre instituições políticas e intergovernamentais), além de fatores históricos, referentes à institucionalização dos setores sociais, como saúde e educação. Este texto representa a primeira etapa de uma agenda de pesquisa sobre as redes de proteção social na América Latina, abordando inicialmente hipóteses explicativas para as políticas de saúde na Argentina, Brasil e Chile.

\section{O CONTEXTO POLÍTICO E ECONÔMICO DAS REFORMAS DAS POLÍTICAS SOCIAIS DOS PAíSES}

As décadas de 1970 e 1980 foram marcadas pela ocorrência de regimes ditatoriais e pela crise da dívida externa, caracterizando um quadro de elevado endividamento, recessão e acirrado processo inflacionário. A partir da década de 1980, a articulação dos processos políticos e econômicos entre os países é muito distinta. Se considerarmos o caso brasileiro de um lado - redemocratização na década de 1980 e aprofundamento de reformas neoliberais na década de 1990 — e o caso chileno do outro — implementação das políticas neoliberais ainda na ditadura e abertura democrática a partir de 1990 - temos o caso argentino com uma dinâmica totalmente distinta — redemocratização nos anos 1980 e liberalização na década de 1970 e, novamente, nos anos de 1990.

Na Argentina de Alfonsín e no Brasil de Sarney, a década de 1980 foi marcada pela tensão entre as lógicas da estabilização econômica e da redemocratização. A lógica centrífuga da redemocratização envolveu a inclusão de novas classes políticas e a redefinição de atores sociais que demandavam maior justiça social. A lógica centrípeta da estabilização econômica demandou uma ação política centralizada e coordenada pelo governo central. Nos dois casos, as experiências heterodoxas de estabilização econômica foram frustradas em ambientes de grande conflito distributivo entre políticos e grupos sociais organizados que buscavam transferir os custos da estabilização e dos ajustes estruturais (SMITH, 1993). A literatura de Ciência Política define esse processo latino-americano de transição dual (SOLA, 1995).

Os resultados desses processos foram distintos nos dois países. No Brasil, a abertura política foi pautada pela grande expectativa de grupos sociais de interferir na estrutura de gastos do Estado e garantir espaço para suas demandas represadas no período autoritário. 
Essa movimentação deu-se pela organização da sociedade civil em setores como os de saúde e educação e pela pressão das unidades subnacionais por maior participação política e reestruturação fiscal. Essa articulação de grupos e esferas de poder culminou em um processo constituinte em 1988 que instituiu a cidadania social, bem como a descentralização da carga tributária entre os entes federativos. Contudo, esta descentralização de poder que se somava à elevação das demandas sociais, ocorria ao mesmo tempo em que o Brasil vivia um momento de crise econômica, com redução do crescimento. A consequência disso foi a queda de arrecadação de impostos, conjugada com o aumento da demanda por gastos públicos (DALL'ACQUA e GUARDIA, 1995).

Na Argentina, nas décadas de 1980 e 1990, houve a convergência de um modelo econômico pautado por um forte financiamento externo e a deterioração das políticas sociais. Além do processo de financiamento externo, houve importantes mudanças de política econômica, implementadas pelo presidente Menem a partir de 1989, que incluíram a abertura de mercados, privatizações e a conversibilidade com taxa de câmbio fixa (BRESSER-PEREIRA, 2002). Com relação às políticas sociais argentinas, o grande destaque do período foi a atuação de organismos multilaterais de crédito como atores formadores de política (ROVERE, 2004).

No Chile, a década de 1980 foi marcada pelo aprofundamento da agenda neoliberal e pelo acirramento da crise do governo Pinochet. Período de recessão econômica causada pelo grande endividamento externo, no governo Pinochet, houve o aprofundamento do processo de abertura econômica e o fortalecimento das exportações como base para uma nova inserção econômica internacional do país. O processo de recuperação econômica foi alcançado no final do governo militar e se ampliou com a abertura democrática a partir de 1990 (ROJAS ARAVENA, 1997). Nesse período, o governo de coalizão democrática enfrentou uma situação bastante crítica nas políticas sociais, a redução de gastos nessa área somada ao arrocho de cerca de $8 \%$ nos salários médios implicou uma piora na distribuição de renda e qualidade de vida das famílias (FFRENCH-DAVIS, 2004).

\section{A institucionalização da rede de proteção social na América Latina e a agenda de saúde do Banco Mundial}

Nos últimos 20 anos, processos de permanências e mudanças caracterizaram as reformas das redes de proteção social na América Latina. Em linhas gerais, Draibe (1997) argumenta que a manutenção de características conservadoras das políticas sociais convivem com a implementação de inovações institucionais importantes, como os processos de descentralização e participação. O quadro de dicotomias e ambiguidades verificado desde os anos 1980 tem raízes históricas profundas: antes dos anos 1970, construíram-se de forma imperfeita as bases do Welfare State na região em razão de dois conjuntos de motivos — os estruturais e os institucionais.

A autora entende por estruturais os processos socioeconômicos de acumulação, em função de mercados de trabalho pouco integrados e níveis baixos de assalariamento. $\mathrm{O}$ resultado desse processo foi a formação de sistemas conservadores de Welfare State, que tenderam a proteger as categorias sociais dotadas de maior poder de organização e de 
excluir benefícios às populações mais pobres e marginalizadas. Em termos institucionais, esses sistemas apresentavam elevada centralização, débeis capacidades regulatórias e de implementação das políticas nos níveis subnacionais de governo, comportamento corporativista e fraca tradição participativa.

Para entender o quadro mais recente de mudanças, também se deve considerar a influência da oferta de ideias das agências internacionais nos países latino-americanos especialmente sobre as políticas de saúde. O início do século XX foi marcado pela difusão de duas correntes doutrinárias em saúde na América Latina: a corrente da saúde pública, que preconizava um modelo centralizado, profissionalizado e padronizado de organização dos serviços e das atividades técnicas, por meio das campanhas sanitárias, a partir das diretrizes da Oficina Sanitária Internacional (desde 1948, a Organização Pan-Americana da Saúde - OPAS) e a Fundação Rockefeller (Labra, 2001). A segunda corrente foi preconizada pela Organização Internacional do Trabalho (OIT) e é vinculada à proteção e recuperação da força de trabalho urbana, a partir do modelo alemão de seguro-doença.

A partir dessas correntes, quatro modelos de sistema de saúde despontaram no cenário mundial: o seguro-doença das caixas de pensões; o sistema estatal e universalista soviético adotado em Cuba após a Revolução de 1959; o Serviço Nacional de Saúde da Grã-Bretanha, criado em 1948 a partir do conceito de Seguridade Social; e os seguros de saúde privados e liberais norte-americanos, com proporção residual de serviços públicos (Labra, 2001). O Chile foi um caso destacado de implementação no início da década de 1950 do modelo inglês, que foi desmantelado na década de 1980 durante o governo Pinochet, sob a égide de que o melhor eixo organizador das relações sociais seria o mercado. No Brasil, em plena onda neoliberal, a reforma sanitarista se concretiza nos trabalhos da Assembleia Constituinte de 1987, impulsionada por forças sociais progressistas que reivindicam a implementação do Sistema Único de Saúde (SUS). Segundo Labra (2001), o caso brasileiro e o chileno adotaram formatos institucionais parecidos, mas tomaram historicamente rumos diametralmente opostos.

Desde a década de 1970, há mudanças importantes que estão ocorrendo na oferta de modelos das agências internacionais para as políticas públicas de bem-estar social e de desenvolvimento econômico em países em desenvolvimento. Nos anos de 1970, o meio de difusão das ideias de agências e fóruns internacionais de discussão era a cooperação técnica e o diálogo político com representantes dos diversos países, a chamada "comunidade do desenvolvimento". Nos anos de 1980, no contexto de crise da dívida externa e de propostas de ajuste estrutural, as ideias se disseminaram a partir de mecanismos de indução, especialmente os empréstimos condicionados à adoção de políticas econômicas liberalizantes. Nos anos de 1990, segundo Mattos (2001), emergiu um novo padrão de atuação das agências caracterizado pela retomada de diálogo entre as próprias agências internacionais e das agências com cada governo, em um quadro de práticas assimétricas que ainda persistiam, de crise do financiamento da "comunidade do desenvolvimento" e de mudança do conteúdo da agenda internacional do desenvolvimento de políticas públicas com o objetivo de reduzir a pobreza.

A comunidade epistêmica de agências internacionais na área de saúde foi formada basicamente por instituições de dois sistemas de organizações internacionais: as Nações Unidas - especificamente a Organização Mundial de Saúde (OMS) —, e as instituições 
de Bretton Woods (BW) - especificamente o Banco Mundial. Nos anos de 1980, as agências de cooperação do sistema das Nações Unidas — OMS e UNICEF — perderam prestígio diante das agências de BW em função da dinâmica dos empréstimos mediante a adoção de políticas neoliberais nos países em desenvolvimento. Os anos de 1990 foram marcados pela proeminência do Banco Mundial no debate das políticas de saúde atrelada a uma estratégia de se diferenciar da instituição irmã FMI e a adesão ao mote de "combate à pobreza" em substituição da bandeira do desenvolvimento. O Banco Mundial apresentava-se como uma das agências com maior capacidade de responder à empreitada de propostas de modelos aos governos e aos demais parceiros da comunidade internacional em virtude de sua experiência mundial, de uma grande estrutura interna para produzir sugestões e de relevante capacidade de mobilização de recursos. Ao final da década de 1980, o Banco Mundial era um dos maiores provedores de recursos externos para a saúde (Mattos, 2001).

Da década de 1970 à década de 1990, o Banco Mundial passa por importantes mudanças no que tange ao conteúdo de políticas de saúde para os países da América Latina. A instituição ingressou no debate apresentando proposta de redução da responsabilidade dos governos no financiamento dos serviços de saúde, pois a melhora verificada nos indicadores estava mais relacionada ao impacto de mudanças tecnológicas do que a mudanças comportamentais causadas por políticas. O critério operacional de delimitação do que o governo deveria pagar seria a disposição da população em pagar pelo serviço. O Banco criticava os governos que viam a saúde como direito e que promoviam o acesso universal a todos os serviços, na medida em que atendiam principalmente os estratos médios da população. Difundiu-se o conceito de "má alocação" e recomendaram-se reformas descentralizadoras, que superariam o "gigantismo burocrático" das estruturas estatais centralizadas (Almeida, 2002). A UNICEF foi a instituição internacional que fez forte oposição às ideias do Banco Mundial, argumentando a partir de experiências exitosas de combate à mortalidade infantil. A política de utilização do soro caseiro, por exemplo, mostrou-se muito favorável entre termos de eficiência e envolveu real mudança de comportamento dos beneficiados (Mattos, 2001).

Em 1993 com o relatório "Investing in Health", o Banco Mundial mudou algumas diretrizes, mas aprofundou outras. Houve uma moderação do discurso de antiuniversalização do serviço, considerando uma abrangência maior, mas condicionando as políticas focalizadas que garantissem o acesso aos pobres, com foco na família e coordenação de políticas públicas e educação da mulher. O Banco, mediante análise dos dados, reconheceu o erro no diagnóstico dos países pobres na década de 1980, ao defender a redução do gasto público em saúde. Nos anos 1990, admitiu-se que era preciso aumentar o gasto público com saúde e era desejável aumentar a ajuda internacional à saúde, ou seja, há intervenções altamente efetivas em termos de custo. Contudo, o banco aprofundou a concepção de que era preciso estender a lógica privada na atuação do setor público na área de saúde.

A ação do Estado deveria se restringir aos grupos sociais mais necessitados, mediante a provisão de uma cesta básica de serviços definida pela relação custo/efetividade. O setor público deveria competir com o setor privado a partir da expansão dos seguros de saúde; deveria haver uma divisão entre financiamento e provisão: financiamento por meio de impostos destinados a determinados fins e dinheiro deveria seguir o paciente e não ser alocado diretamente para as unidades prestadoras do serviço; o gerenciamento do sistema deveria ser fortemente descentralizado. 
Os países que implementaram a receita do Banco Mundial de forma mais assertiva foram o México e a Colômbia. Santos e Ugá (2007) destacam também a Argentina, como um caso de crescimento do setor privado com finalidade de lucros, que se somou às Obras Sociales. O Brasil seguiu um caminho notadamente diferente na América Latina, com o Sistema Único de Saúde convivendo com uma estrutura pré-existente de planos e seguros privados.

\section{Políticas de saúde no Brasil, Argentina e Chile}

Diante do quadro abordado, houve mudanças importantes nas redes de proteção social do Brasil, da Argentina e do Chile. A partir da análise das políticas de saúde, podemos levantar hipóteses de como esse processo ocorreu, considerando as inter-relações de grupos sociais organizados, atores políticos subnacionais e o histórico conservador de institucionalização das políticas sociais na América Latina.

A análise das implementações das políticas de saúde na América Latina demonstra a existência de distintas modalidades de reforma dos sistemas. Alguns países foram paradigmáticos na implementação das recomendações internacionais. Conforme Almeida (2002), o Chile foi o caso mais radical ao adotar a privatização como cerne da reforma, combinando "seguros privados, competencia en el aseguramiento y segmentación de la estrutura de financiamiento" (Almeida, 2002, p. 921). A Argentina, por sua vez, "es ejemplo de los intentos de introducir cambios en un sistema universal, también mixto, pero fuertemente segmentado y controlado por grupos corporativos, debido a la importancia de la seguridad social en su estructuración" (idem). O caso brasileiro tem uma forte influência do processo de redemocratização "(...) y es un intento de consolidar un sistema único de salud, público, universal y descentralizado, basado en la concepción de salud como derecho de ciudadanía y deber del Estado, aparentemente en una ruta contraria a la dinámica mundial" (Almeida, 2002, p. 921 ).

Apesar de Brasil e Argentina serem países federativos e o Chile um país unitário, nos três casos é possível observar a implementação de sistemas de saúde marcados pelos elementos indicados por Draibe (1997). Trata-se de sistemas de saúde altamente excludentes, heterogêneos e fragmentados, bastante resistentes à pretensão reguladora do aparelho estatal (BUSS e LABRA, 1995). Especificamente, o elemento corporativista ligado à atuação da representação da classe médica explica parcialmente essas características dos sistemas em momentos históricos distintos.

O Chile destaca-se na região por ter implementado, desde o século XIX, amplas e bem-sucedidas políticas de educação e saúde, que garantiram ao país índices sociais bastante elevados em relação a seus vizinhos. No início do século passado, o tema da saúde pública dividia o país em três correntes de interesses: a direita conservadora, que defendia um regime público de saúde preventiva para os miseráveis e desvalidos; o centro, que propugnava um modelo de assistência preventiva nos moldes da Organização Internacional do Trabalho (OIT) voltado aos assalariados e separado da saúde pública; e as esquerdas, que defendiam um sistema único, público, integral e de qualidade (Labra, 2000). Em 1952, criou-se a base do Estado de Bem-Estar Social na Saúde, o Seguro Nacional de 
Saúde, que foi fruto, entre outros fatores, da mobilização da sociedade civil e dos profissionais da saúde. No entanto, apesar da forte presença política da classe médica, o governo Pinochet implementou modificações privatistas: a criação de 27 superintendências regionais de saúde e o consequente esvaziamento do Ministério da Saúde; a municipalização da atenção básica; a criação do Fundo Nacional de Saúde; e a redução dos recursos públicos destinados à saúde. A área da saúde é emblemática do processo de destruição que o autoritarismo causou no quadro da "medicina socializante" da primeira metade do século XX, nas prerrogativas de cidadania e na articulação que havia entre estruturas estatais e grupos sociais organizados.

Em 1980, a Constituição imposta pelo regime ditatorial criou um sistema coordenado de saúde privada, de aderência voluntária e sustentado por subsídios governamentais. Apesar da prevalência da agenda neoliberal e o seu inegável impacto no sistema de saúde pública com o crescimento dos serviços privados, a memória da sociedade chilena de mobilização dos profissionais de saúde em direção à criação de um sistema público e universal ainda persiste. Os governos democráticos, por vezes, têm dificuldades contingenciais para buscar um modelo naqueles moldes, ainda que existam travas constitucionais deixadas pela ditadura, restrições orçamentárias e um debate público polarizado. Atualmente, um amplo modelo privado de serviços de saúde coexiste com um colchão mínimo de provisão desses serviços para a população de baixa renda.

Na Argentina, os serviços de saúde estiveram historicamente submetidos ao sistema político do país. O corporativismo, crescente no período peronista, centralizava essas políticas no Ministério do Trabalho e na Fundação María Eva Duarte de Perón. O resultado foi a institucionalização das Direcciones Generales que marcaram, nos 50 anos subsequentes, um sistema fragmentário, heterogêneo, capturado por grupos organizados e altamente descoordenado. Em 1949, a reforma constitucional incorporou os direitos sociais à Carta Magna, contudo sem explicitar como se daria o financiamento do sistema de serviços. $\mathrm{Na}$ década de 1950, a autodenominada Revolução Libertadora teve como principal estratégia o desmonte da estrutura de serviço público herdada do período anterior. A sucessão de governos civis e militares marcou contradições que se manifestaram num movimento pendular de transferência de serviços nacionais para as províncias pelos militares e o retorno para as esferas federais pelos civis nos débeis governos democráticos que se seguiram (ROVERE, 2004).

A forma descoordenada da descentralização administrativa nas províncias e seus resultados, a partir do final dos anos 1970, podem ser explicados pelos elementos históricos da área de saúde: escassa eficiência dos gastos, sobreposição de funções, baixa coordenação na regulação e nas fiscalizações. Nos últimos 20 anos, a Argentina continuou a carecer de um plano nacional de saúde que possa unificar a miríade de subsistemas desenvolvidos localmente e altamente excludentes.

[...] La Ley de Seguro Nacional de Salud se sanciona en 1988 bajo el número 23.661 pero la Ley nunca fue reglamentada. Lo cierto es que desde el abandono del Seguro Nacional de Salud en adelante nunca más se llevó a discusión el problema de la universalidad del sistema de salud en la Argentina. (ROVERE, 2004, p. 7.)

No Brasil, a concepção de cidadania regulada (SANTOS, 1987) está na base do processo de organização das políticas de saúde. Nas décadas de 1930 e 1940, a assistência médica era 
prestada por uma previdência social incipiente. Caminhou-se de um "sanitarismo campanhista" (início do século XX até os anos 1960) para um "modelo médico-assistencial privatista" (a partir de meados dos anos de 1960 até a década de 1980) (BUSS e LABRA, 1995). Observa-se que o processo de redemocratização nos anos 1980 foi acompanhado pela formulação de um sistema público gratuito e universal de saúde, cuja implementação conviveu com o crescimento de uma vasta rede privada de serviços de saúde. O caso brasileiro apresenta um processo político-institucional descentralizador, no qual os municípios acumularam importantes atribuições na oferta dos serviços no processo de institucionalização do Sistema Único de Saúde (SUS).

O caso brasileiro diferencia-se dos casos argentino e chileno por conta da forte atuação, desde os anos de 1970, ainda no auge da ditadura, e, sobretudo no período de transição para o regime democrático, de um combativo movimento sanitarista. Embora não seja tão antigo quanto a militância pela saúde pública chilena, o sanitarismo brasileiro, surgido no início do século XX, foi um ator fundamental no processo de elaboração do capítulo sobre seguridade social da Constituição de 1988. Naquela oportunidade, os sanitaristas defenderam a criação de um sistema universal de saúde, público, gratuito e de qualidade, totalmente financiado por recursos públicos. Além disso, defendiam que a participação do setor privado no provimento de serviços se desse por regime de concessão e trabalharam ainda pela crescente descentralização dos serviços de saúde.

Apesar das conquistas constitucionais, esse grupo não foi totalmente bem-sucedido, pois a atuação dos interesses organizados das empresas de saúde privada fez constar da nova Constituição a temática da cobertura particular, com atuação complementar em todas as ações de saúde. Além disso, os sanitaristas não conseguiram fazer com que as fontes de recursos para o financiamento da saúde pública deixassem de ser majoritariamente federais, ainda que a concentração dos recursos em Brasília pudesse contribuir para a eventual redução da desigualdade da prestação dos serviços de saúde nos níveis subnacionais. Um breve balanço do período que se estende da promulgação da Carta até os dias de hoje mostra que houve avanço do SUS: descentralização crescente das fontes de recursos para a provisão dos serviços, melhoria de diversos indicadores de saúde e aumento da cobertura privada de saúde entre diversos segmentos da população. O país ampliou o acesso da população a serviços públicos de saúde, caracterizando-se assim uma política pública mais eficaz, eficiente e efetiva, ao mesmo tempo em que importantes parcelas da sociedade migraram para o sistema privado.

\section{Considerações Finais}

A análise dos casos de Argentina, Brasil e Chile em relação à evolução recente das políticas públicas da área da saúde demonstra que, embora submetidos à agenda internacionalmente difundida pelo Banco Mundial e pelos demais organismos multilaterais em relação às políticas sociais e a despeito de elementos corporativistas comuns que marcaram o histórico desses sistemas, do contexto de crise econômica e mudança política, os três países trilharam caminhos distintos. $\mathrm{E}$ isso se deveu a diversos fatores, entre os quais destacamos: 
a) legado institucional e político que cada nação trazia à época em que adotou as medidas preconizadas pelas instituições multilaterais foi um elemento fundamental para que a receita única difundida pelo Banco Mundial fosse adotada de maneiras distintas em cada país e, sobretudo, tivesse consequências bastante diferentes em cada contexto nacional, apontando para a questão da path dependence como um dado central para análises de políticas públicas em perspectiva comparativa. Mesmo num contexto comum de reformas orientadas para o mercado, nas quais o elemento da redefinição do papel do Estado e dos custos de seu funcionamento fosse muito relevante, os resultados alcançados nas políticas públicas de saúde foram significativamente distintos nos três casos analisados. Sob a nossa ótica, o caso brasileiro destaca-se como um caso de reforma incremental em um sistema de saúde com traços de mudanças e permanências. Em um contexto político e econômico no qual a descentralização das políticas sociais apresentou um duplo significado - democratização e eficiência —, a construção do sistema público de saúde foi marcada por um processo de negociação entre grupos sociais organizados e atores políticos subnacionais, porém ainda capitaneado pelas instâncias políticas do Governo Federal. Acreditamos que o caso argentino, a despeito de ser um país federativo como o Brasil (com relações federativas distintas), apresenta características próximas ao caso chileno no que tange ao histórico do sistema de saúde e seus impactos nos processos contemporâneos de reforma.

No caso chileno, houve historicamente importantes experiências socializantes de constituição de um amplo sistema nacional e gratuito de saúde, sustentado por grupos sociais organizados, e duramente combatido pelo governo autoritário. Tanto naquele caso quanto no caso da Argentina os movimentos de centralização e descentralização administrativa foram instrumentos de poder de governos democráticos e autoritários, respectivamente. O histórico de desmonte das estruturas públicas e gratuitas de serviços de saúde é um dos elementos que explica, por exemplo, a falta de regulamentação da Lei de Seguro Nacional de Saúde sancionada em 1988 na Argentina e a existência de um sistema altamente fragmentado e segmentado no Chile. A prevalência da pauta econômica neoliberal - implementada radicalmente na Argentina e no Chile - na agenda mais recente de descentralização das políticas de saúde também configura como um importante elemento desta hipótese de pesquisa que será investigada em trabalhos vindouros;

b) descentralização das políticas sociais e, especificamente, das políticas de saúde, teve distintos significados nos três países. No Brasil, o processo pode ser entendido como uma conquista do movimento sanitarista, que tinha na pactuação entre os entes federativos e as populações locais para a formulação das políticas públicas de saúde uma de suas mais importantes bandeiras, ainda que se leve em conta que, hoje, as decisões estratégicas permanecem concentradas no Ministério da Saúde e a estados e municípios caibam tarefas muito mais voltadas à implementação de programas. No Chile, o processo de descentralização foi um experimento adotado durante a ditadura militar, e não carregou em si qualquer objetivo de ampliação dos canais de interlocução entre Estado e sociedade civil e aprimoramento de práticas democráticas, mas, antes, foi pautado pelo viés da eficácia e da competição, que se acreditava serem mais alcançáveis a nível local. Na Argentina, por outro lado, o processo de descentralização pareceu 
sofrer, ao longo do século XX e mesmo no período mais específico dos últimos trinta anos, idas e vindas, não deixando de ter relações com a problemática maior do complexo modelo federalista daquele país;

c) diferentes formas de relações entre o Estado e os atores sociais existentes no setor da saúde também se destacaram em nossa análise. O Chile é o caso mais paradigmático de um movimento sanitarista forte, tradicional, politizado, reunindo parcela importante da classe médica, da intelectualidade e de setores populares. Tão forte a ponto de ter conseguido resistir à empreitada privatizante levada a cabo pelo governo militar e fazer renascerem, após o retorno à democracia, as suas principais bandeiras. A Argentina, por seu turno, é um caso em que as classes populares puderam ter acesso à saúde pública na medida em que estivessem inseridas nas teias corporativistas das relações com o Estado, ao mesmo tempo em que a classe médica, em sua maioria, pareceu comportar-se, ao longo do tempo, mais como um agente econômico do que como um ator político, contrariamente ao observado no Chile. O Brasil, neste contexto, surge como um caso intermediário entre os outros dois. Jamais logramos ter, em nosso país, um movimento sanitarista tão antigo e tão forte politicamente como o que teve o Chile, porém o sanitarismo brasileiro foi, sobretudo nos anos de 1970 e 1980, um ator político bastante influente, de fundamental importância para o redesenho de todo o sistema de saúde pública previsto pela Constituição de 1988 e de promoção social da saúde. Por outro lado, tivemos no Brasil um setor privado também muito forte, que conseguiu fazer prevalecer alguns de seus interesses na promulgação da nova Carta e que, nos últimos anos, experimentou formidável aumento na provisão de serviços de saúde à população, a partir inclusive das novas modalidades de relacionamento que passou a estabelecer com o Estado brasileiro, nos três níveis de governo.

Enfim, a reflexão esboçada nas páginas acima sugere que as políticas sociais, que se constituem hoje como uma importante face do desenvolvimento das nações, alcançam resultados distintos, mesmo que sofrendo forte influência de ideias difundidas pelas poderosas organizações multilaterais, por conta dos padrões institucionais, políticos e sociais prévios, característicos de cada país. Como vimos, este fator foi importante a ponto de o próprio Banco Mundial ter mudado, ao longo do tempo, determinadas características de sua agenda, na qual originalmente as políticas públicas, especialmente as da área social, estiveram sempre submetidas à racionalidade econômica em sentido mais amplo.

\section{REFERÊNCIAS BIBLIOGRÁFICAS}

ALMEIDA, Célia. Reforma de sistemas de servicios de salud y equidad en America Latina y el Caribe: algunas lecciones de los años 80 y 90. Caderno de Saúde Pública, Rio de Janeiro, v. 18, n. 4, p. 905-925, jul./ago. 2002.

BRESSER-PEREIRA, Luiz Carlos. Financiamento para o subdesenvolvimento: O Brasil e o segundo consenso de Washington. BNDES, 2002.

BUSS, Paulo Marchiori e LABRA, Maria Eliana (Orgs.). Sistemas de saúde, continuidades e mudanças: Argentina, Brasil, Chile, Espanha, Estados Unidos, México e Québec. São Paulo: Hucitec, 1995. 
DALL'ACQUA, Fernando M.; GUARDIA, Eduardo R. Análise do sistema orçamentário no Brasil. São Paulo, FGV-SP, 1995. (Pesquisa apresentada ao Núcleo de Pesquisa e Projetos da EAESP-FGV).

DRAIBE, Sonia. Uma nova institucionalidade das políticas sociais? Reflexões a propósito da experiência latino-americana recente de reforma dos programas sociais. Revista São Paulo em Perspectiva, São Paulo, v. 11, n. 4, p. 3-21, 1997.

FFRENCH-DAVIS, Ricardo. Entre el neoliberalismo y el crescimiento con equidad: tres décadas de política económica en Chile. 1. ed. Buenos Aires: Siglo XXI Editores, 2004.

LABRA, Maria Eliana. Padrões de formulação de políticas de saúde no Chile no século XX. Dados, Rio de Janeiro, v. 43, n. 1, 2000.

LABRA, Maria Eliana. Política e saúde no Chile e no Brasil. Contribuições para uma comparação. Ciência e Saúde Coletiva, v. 6, n. 2, p. 361-376, 2001.

MATTOS, Rubens de Araújo. As agências internacionais e as políticas de saúde nos anos 90: um panorama geral da oferta de ideias. Ciência e Saúde Coletiva, v. 6, n. 2, p. 377-389, 2001.

ROJAS ARAVENA, Francisco. Chile: mudança política e inserção internacional, 1964-1997. Revista Brasileira de Política Internacional [on-line], v. 40, n. 2, p. 49-75, 1997.

ROVERE, Mario. La salud en la Argentina: alianzas y conflictos en la construcción de un sistema injusto. Revista Electrónica La Esquina del Sur, maio 2004. Disponível em: <http:// www.laesquinadelsur.com.ar/site/index.asp?Ed=7> Acesso em: 1ํ jul. 2010

SANTOS, Angela M. S. P.; UGÁ, M. A. D. Reformas do Estado, descentralização e políticas de saúde: uma análise comparada entre Argentina, Brasil, Colômbia e México. Ensaios FEE, Porto Alegre, v. 28, n. 2, p. 525-548, out. 2007.

SANTOS, Wanderley G. Cidadania e Justiça. As políticas sociais na ordem brasileira. São Paulo: Campus, 1987.

SMITH, William C. Estado, mercado e neoliberalismo na Argentina pós-transição: a experiência Menem. In: SOLA, L. (Org.). Estado, mercado e democracia. São Paulo, Paz e Terra, 1993.

SOLA, Lourdes. Estado, reforma fiscal e ordem monetária: qual Estado? In: SOLA, Lourdes; PAULANI, Leda (Orgs.). Lições da década de 80. São Paulo: EDUSP, 1995. p. 29-74. 